\title{
Knowledge on HIV prevention amongst a group of post war re-settlers
}

\section{in Sri Lanka}

\author{
de Silva AHW', Rizwaan MSA², Ramanayake P J C ${ }^{3}$, Perera DP', Sumanasekara RDN ${ }^{1}$
}

\begin{abstract}
:
Background:

The war that prevailed for the past three decades in the North and East of Sri Lanka impeded HIV prevention activities in these areas. The purpose of this study is to assess knowledge on HIV prevention amongst post war re-settlers in Thallavadi-Elephant Pass; Northern Province, Sri Lanka.
\end{abstract}

\section{Objective:}

This study assesses the knowledge on HIV prevention amongst post war re-settlers attending a health awareness programme in the community.

\section{Methods:}

Descriptive cross sectional study was carried out on 27th January 2012, using a pretested selfadministrated questionnaire amongst all consenting participants before commencement of the educational activities. All questions were close ended and replies were based on three answers-Yes/No/Don't know. No details of identification were included in the questionnaire and responders were requested to place the filled questionnaire in a sealed box to ensure anonymity. Responders who have never heard of HIV were excluded on analysing knowledge on HIV.

\section{Results:}

One hundred and twelve post war re-settlers took part in the health awareness programme and $81(54 \%$ males) submitted the filled questionnaire. Seventy one $(87 \%)$ respondents had heard of HIV. Only $14 \%$ identified that a HIV infected person may look healthy. Majority $70 \%$ knew that treatment can improve quality of life of infected persons. 94\% recognized condoms as a HIV prevention method.

\section{Conclusion:}

$17 \%$ of participants answered correctly to all four variables of the UNGASS indicator 13: knowledge on HIV. The knowledge on HIV prevention amongst this group of post war re-settlers is very low.

Key words: HIV, knowledge on prevention, postwar re-settlers

\section{Introduction:}

The war that prevailed for the past three decades in the North and East of Sri Lanka impeded HIV prevention activities in these areas. This study was conducted during the awareness programme for the post-war re-settlers at the Thalavady village in Elephant Pass in the Northern Province of Jaffna. This programme was organised by 55 division of the Sri Lanka army to the public of the re-settlers village! This study was carried out prior to the awareness programme. The purpose of this study is to assess knowledge on HIV prevention amongst post war resettlers in Thalavady resettlement village.

The first HIV-infected person in Sri Lanka was reported in 1986, and since then over 1739 cases of HIV has been reported in Sri Lanka ${ }^{2}$. The estimate number of HIV was 4200 in 2011 statistics². The future course of the HIV/AIDS epidemic depends on a number of variables. As there is no cure for

\footnotetext{
${ }^{1}$ Lecturer, ${ }^{3}$ Senior Lecturer, Department of Family Medicine, Faculty of Medicine, University of Kelaniya, Sri Lanka. ${ }^{2}$ Senior Registrar-Venereology, National STD/AIDS Control Programme, Sri Lanka.

Corresponding author: Rizwaan MSA, Email: msarizwan@gmail.com
} 
HIV/AIDS, important strategies to minimize HIV/ AIDS prevalence include: comprehensive knowledge among people on how HIV/AIDS is transmitted; prevention of HIV/AIDS by taking precautions; promotion of positive attitudes, accepting attitudes and perceptions about HIV-infected people; and reduction in the social stigma attached to HIV/ AIDS $^{3}$.

In the absence of a cure or a vaccine for HIV/AIDS, preventive measures contribute immensely to reducing the spread of the infection. This can be achieved only if individuals have accurate knowledge about the infection.

In the 2006-07 Sri Lanka Demographic and Health Survey (SLDHS), information was collected from ever-married women age 15-49, and data are presented at the national level as well as within different subgroups. According to this survey, 92 percent of ever-married women have heard of HIV/ AIDS, but there are notable differences among subgroups. Although ever-married women from urban and rural areas have a very high awareness about HIV/AIDS ( $94 \%$ for both groups), only 47 percent of their counterparts living in the estate areas are aware of HIV/AIDS. Only 64 percent of evermarried women in Nuwara Eliya District - which predominantly consists of estates - have heard of the disease, compared with well over 80 percent of women in all the other districts. In four districts (Colombo, Gampaha, Kurunegala, and Polonnaruwa), HIV/AIDS awareness is over 95 percent $^{4}$.

In 2011, there were 34 million (31.4-35.9) HIV infected persons around the world, with young people age 15-24 accounting for 45 percent of new infections in adults ${ }^{5}$. In combating HIV/AIDS, it is of the utmost importance to improve knowledge among youth between 15-24 years as well as to promote safe sex practices, especially among teenagers and young adults. The results indicate that only 1 in 5 evermarried young women has comprehensive knowledge of HIV/AIDS, though slightly more than half of them know where to get condoms ${ }^{6}$.
According to the study conducted among Sudanese men and women in Dimma refugee settlement in South-western Ethiopia in 1992, 73 per cent reported that they heard of HIV or AIDS ${ }^{7}$. There was another comparison cross-sectional study which was. conducted in Afghanistan between injecting drug users and former refugees in 2005. This study revealed that the awareness of HIV was reported by $46.1 \%$; those having been outside the country in the last decade were significantly more likely to have heard of HIV ( $48.3 \%$ vs. $31.7 \%$; OR $=2.00,95 \%$ CI: 1.143 .53 ). However, of those aware of HIV, only $38.3 \%$ could name three correct transmission routes; specific HIV knowledge was not significantly associated with residence outside the country ${ }^{8}$.

The study from Sierra Leone in 2002, among the general pepulation in the post-war period, $89 \%$ of women and $82 \%$ of men could correctly identify three modes of transmission of HIV/AIDS at baseline, by the time of the follow-up survey $95 \%$ of women and $97 \%$ of men could do so $^{9}$.

\section{Methodology:}

This study was carried out on 27th January 2012. There were one hundred and twelve post war resettlers involved in the study. A pretested, confidential anonymous self-administered questionnaire was used amongst all consenting participants before commencement of the educational activities. UNGASS indicator number 13 variables were used in the questionnaire. All questions were close ended and replies were based on three answers - Yes $/ \mathrm{No}$ / Don't know. No details of identification were included in the questionnaire and responders were requested to place the filled questionnaire in a sealed box to ensure anonymity. Responders who have never heard of HIV were excluded on analysing knowledge on HIV. 


\section{Results:}

One hundred and twelve post war re-settlers took part in the health awareness programme and $81(54 \%$ males) submitted the filled questionnaire. The majority of the sample (70\%) was between 15-49 years of sexually active age group. In addition, fifty three per cent of participants belonged to the age group of 15-35. Mean age of the participants was 37.7 years with an age range of $15-75$ years.

$45.7 \%$ of the participants were educated up to ordinary level and advanced level $(30.9 \%)$. The majority of the sample were housewives $(25.9 \%)$ whilst $14.8 \%$ of them were unemployed. Furthermore, approximately sixty per cent of the respondents were engaged in regular form of employment.

Seventy one $(87.7 \%)$ respondents had heard of HIV. There was no statistical significance between having heard of HIV and the level of education. In the sample, almost half of the respondents knew that HIV could be transmitted via an infected person. Likewise, sixty three per cent of the respondents knew that HIV could spread through sharing needles. On the other hand, half of the people were not aware that through mosquitoes and sharing bed linen and cloths with a HIV infected person, HIV would not lead to transmission of HIV. However, that trans-placental HIV transmissions occurs from mother to baby was well known by nearly $93 \%$ of respondents. Only $14 \%$ identified that a HIV infected person may look healthy. Majority $(70 \%)$ knew that treatment could improve the quality of life of infected persons. Seventy six $(93.8 \%)$ people have had sexual relationship in their life time. Moreover, 94\% recognized condoms as a HIV prevention method.

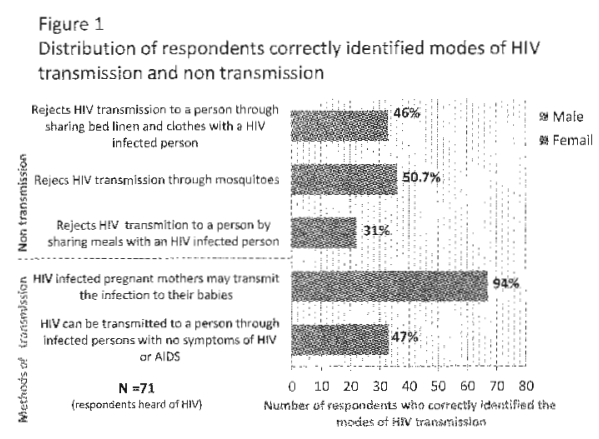

From the total respondents, $17(21 \%)$ ever used a condom with their partner. [Male-12; Female-5]. There was no association between condom use and having heard about HIV. $(p=1)$

Percentage of respondents who both correctly identify the ways of preventing the sexual transmission of HIV (variable $1 \& 2$ ) and who reject major misconceptions (variable $4 \& 5$ ) about HIV transmission (adopted from UNGASS indicators on universal knowledge of the essential facts about HIV transmission; March 2009) ${ }^{6}$ was $17 \%$. Only one respondent correctly answered to all 5 variables of the UNGASS indicator 13 which reveals percentage of young women and men aged 15-24 who both correctly identify ways of preventing sexual transmissions of HIV and who reject major misconceptions about HIV transmission.

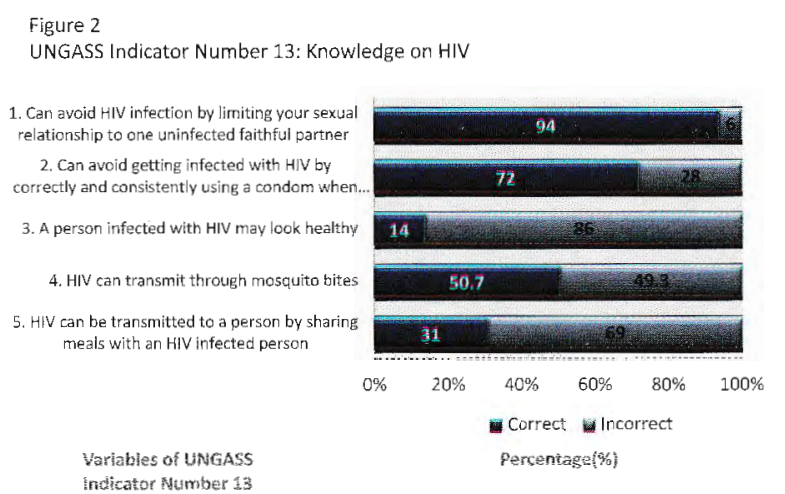

\section{Discussion:}

Figure 3

Knowledge on HIV and Prevention

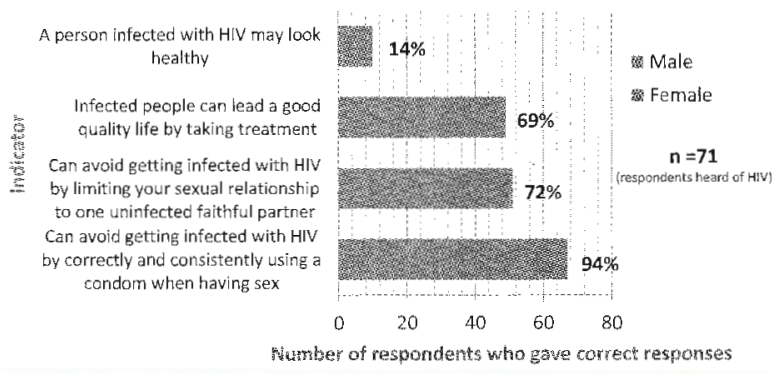

Only $14 \%$ ident fied that a HIV infected person may look healthy. Majority $70 \%$ knew that treatment can improve quality of lite of infected persons, $94 \%$ recognized condoms as a HIV prevention method. 
This is the first report from Sri Lanka, regarding HIV knowledge among post re-settlers. The knowledge on HIV prevention amongst this group of post war re-settlers is very low. Several of re-settlement villages had been developed in many parts of the Northern Province. People have been coming from various parts of the country to their native villages after the long term war. They face innumerable problems related to social, psychological and sexual issues. Furthermore, they have lost their beloved ones and partners in the war. Therefore, it is necessary to educate on sexually transmitted diseases and HIV/ AIDS.

Refugees do not necessarily display higher rates of HIV/AIDS infection than do non-refugee populations, but the trying conditions under which they live often leaves them susceptible to disease. The loss of family, property, food security, access to health care and education can provide a fertile breeding ground for the spread of HIV ${ }^{10}$. Refugees can flee from conflict - but they can't always outrun disease.

\section{Limitations:}

There were several limitations to this study. First of all, the size of the sample limits the generalizability of the findings. Ideally, this should have been done in a randomly selected sample of post war re-settlers in different parts of the Northern Province. However, it was difficult due to several issues such as time, accessibility and financial constraints.

\section{Recommendations:}

More awareness programmes should be done for post war re-settlers. Attempts should be made to explore ways of delivering important health messages to the public during warfare and post war period.

\section{Conflict of interest}

The authors declare no conflict of interest

\section{Funding}

Department of Family Medicine, University of Kelaniya, Ragama

\section{References:}

1. http://www.army.lk (accessed 24 February 2012)

2. http://www.aidscontrol.gov.lk (accessed 16 July 2013)

3. UNGASS Report Sri Lanka, United Nations General Assembly Special Session on HIV Country progress report - Sri Lanka 2008-2009

4. Sri Lanka Demographic and Health Survey 200607 Colombo: Department of Census and Statistics; 2009

5. UNAIDS Worlds AIDS Day report, 2012

6. Monitoring the Declaration of Commitment on HIV/AIDS : guidelines on construction of core indicators: 2010 reporting. UNAIDS 2009

7. Bethany YH et al. Sudanese men and women in Dimma refugee settlement in South-western Ethiopia in 1992, Disaster, 2003, 27 (1):1-15

8. Catherine ST et al. Association between expatriation and HIV awareness and knowledge among injecting drug users in Kabul, Afghanistan: Across-sectional comparison of former refugees to those remaining during conflict, Conflict and Health 2007, 1:5

9. Doris B, Diane L, Tackling HIV/AIDS in postwar Sierra Leone, Forced Migration Review 19: 24-25 http://www.fmreview.org/en/FMRpdfs/ FMR19/FMR 1910.pdf (accessed on 16 July 2013)

10. Vidhanapathirana $\mathbf{J}$ et al. Knowledge \& attitudes on HIV/AIDS among school children in Sabaragamuwa, National STD/AIDS Control Programme, Sri Lanka; 2009. 